\title{
Chemical behaviours of Arsenium, Chromium, Mercury, Lead, and Strontium in aqueous system
}

\author{
Qiuyu Zhao ${ }^{1}$, Siyi Wang ${ }^{1}$ and Jianjun Wang ${ }^{1, a^{*}}$ \\ ${ }^{1}$ MOE Key Laboratory of Resources and Environmental Systems Optimization, College of Environmental Science and Engineering, North \\ China Electric Power University, Beijing 102206, PR China
}

\begin{abstract}
Over the decades, the application of heavy metals and the expansion of civilization resulted in severe pollutions in aqueous solutions. The poor degradation of toxic heavy metal contaminants in hydrosphere undoubtedly posed a huge threat to environmental safety and biological health. In this review, as most common heavy metal pollutants, arsenium (As), chromium (Cr), mercury ( $\mathrm{Hg}$ ), lead $(\mathrm{Pb})$, and strontium (Sr) were introduced in detail. The chemical behaviours, chemical status, biological toxicity, and migration of mentioned contaminants were summarized. This work highlighted and reviewed the basic information of five heavy metal pollutants, which provided a new direction of toxic heavy metal ion remediation.
\end{abstract}

\section{Introduction}

In the process of human development, the utilization of heavy metal greatly promoted the advancement of civilization. However, the heavy metal pollutions also arose several environmental problems because of the improper disposal, accidentally leaked and illegal discharge. Most of the heavy metal pollutants would cause varying degrees of damage to human beings and natural environment, thus, which aroused worldwide attention to address these issues [1]. The accumulating and enriching of heavy metal ions in aquatic organisms and microorganisms were widely existed. Adverse effects on the life activities of organisms will occur when the concentration and toxicity threshold of pollutants are exceeded [2, 3].

Arsenium (As), Chromium (Cr), Mercury (Hg), Lead $(\mathrm{Pb})$, and Strontium $(\mathrm{Sr})$ are most common heavy metal pollutants, which existed world widely. The environment problems caused by mentioned pollutants in aqueous system received great attention and numerous investigations had focused on them [4]. The worrisome aftereffects of drinking water pollution by these heavy metals have blowed up from the 19th century to the 20th century during the period of vigorous development of heavy industry $[5,6]$. Thereinto, several typical cases attracting worldwide attention: itaiitai disease events $(\mathrm{Cd})$, Japan minamata disease events $(\mathrm{Hg})$ and the arsenic poisoning of Bangladesh groundwater.

Considering the hazards of heavy metal pollution, there is much talk about water crisis, of which the most worrying is that hundreds of millions of people lack access to clean and safe water just for their daily consume and the condition is becoming serious with the impetuous development of industry. This grim situation became an inevitable problem in the industrial society. This work reviewed chemical behaviours of common toxic metal ions in solution, and their transformation in aqueous system was briefly introduced. This review summarized the environmental behaviours of $\mathrm{As}, \mathrm{Cr}, \mathrm{Hg}, \mathrm{Sr}$, and $\mathrm{Pb}$, which provided new direction of toxic heavy metal ion remediation.

\section{Arsenium}

Arsenic, an element widely existed in the environment, ranks 20th in nature and 14th in seawater [7]. As an essential trace element of human body, arsenic deficiency can lead to intrauterine growth retardation, bone mineralization, and significantly affect the activity of certain enzymes involved in neurological disorders and vascular diseases. Due to the low demand of arsenic (220 $\left.\mu \mathrm{g} \cdot \mathrm{day}^{-1}\right)$, human can receive adequate amounts from normal diets such as seafood and grains.

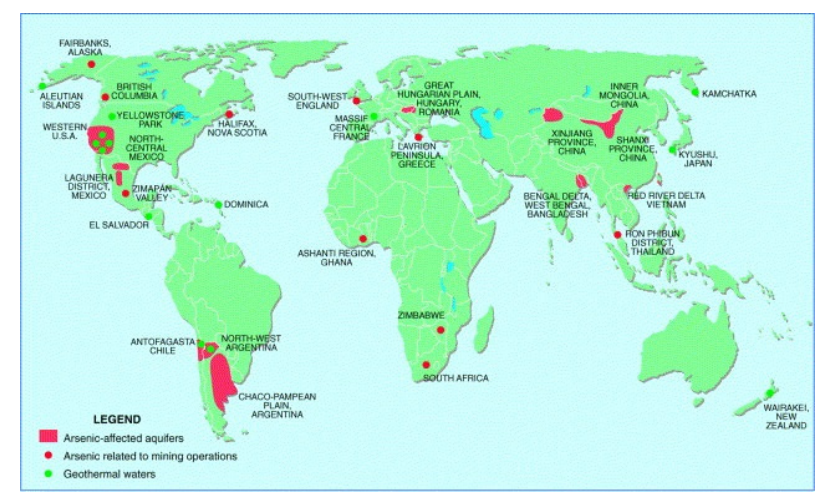

Figure 1. Distribution of Arsenic environmental problems due to mining and geothermal resources [8].

Arsenic is widely existed in groundwater (Figure. 1), rocks, and minerals [8, 9]. However, due to surging demand of human and rapid industrial development, large

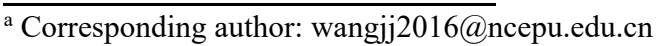


amounts of arsenic are released into nature. Major anthropogenic sources of As in environment are from industrial processes (mining, steel production, and fossil fuels), agriculture production (the use of pesticides, preservatives, and rodenticides), and infant industry (raw material for semiconductor and laser device) $[6,10]$. According to WHO regulations, the concentration of arsenic in drinking water should be limited to $10 \mu \mathrm{g} / \mathrm{L}$. However, in untreated groundwater, the dissolved arsenic is generally higher than the recommended concentration. Regardless of trivalent and pentavalent As, excessive As may cause arsenic poisoning. Among them, As(III) and its oxide $\left(\mathrm{As}_{2} \mathrm{O}_{3}\right)$ are the most toxic because they can react with sulfur-containing compounds to generate reactive oxygen species. The clinical manifestations of acute and subacute arsenic poisoning are initially general discomfort, fatigue, headache, dizziness, etc., followed by nausea, abdominal pain, and diarrhoea.

Chronic arsenic poisoning increases the risk of lung, skin, bladder, and liver cancer [11]. Up to now, there is no effective medicine or treatment for arsenic poisoning. It is recommended to take a range of preventive measures, such as drinking qualified water, taking supplements such as vitamins and proteins, and exercising to improve body function [12]. The geochemistry of arsenic reveals that the mutual conversion and solubility of $\mathrm{As}(\mathrm{III})$ and $\mathrm{As}(\mathrm{V})$ in water depends on a number of factors, including redox potential (Eh), $\mathrm{pH}$, organic content, and aquatic bioactivity. These environmental conditions undoubtedly affect the migration and transformation of many arsenic species in nature [13].

\section{Chromium}

Chromium widely exists in nature, and its natural source is mainly weathering of rocks, mostly in the form of $\mathrm{Cr}$ (III). Sources of man-made pollution include leather preparations, chrome plating of metal parts, industrial pigments, as well as the production of tanned leather, rubber and ceramic raw materials. As depicted in Figure. 2 , different reaction mechanisms in atmosphere, water, and soil greatly affected the biogeochemical cycle of Chromium [14].

The chromium produced by industrial pollution is mainly a hexavalent compound, usually presents as chromate ion $\left(\mathrm{CrO}_{4}{ }^{2-}\right)$. The migration and transformation behaviours in the environment of chromium ions in different valences are also different. For example, $\mathrm{Cr}$ (III) in water can be adsorbed on solid matter and also would exist in sediment. However, $\mathrm{Cr}(\mathrm{VI})$ is more soluble and stable than $\mathrm{Cr}$ (III) in water, and can be reduced to $\mathrm{Cr}$ (III) under anaerobic conditions. $\mathrm{Cr}$ (III) can undergo a hydrolysis reaction under neutral or alkaline conditions, producing insoluble $\mathrm{Cr}(\mathrm{OH})_{3}$ then sinking into the bottom of the water. Therefore, $\mathrm{Cr}(\mathrm{III})$ and $\mathrm{Cr}(\mathrm{VI})$ can easily convert into each other in aqueous solution. Deserved to be mentioned, $\mathrm{Cr}$ (III) is a trace element necessary for human and animal, which is the subsequent component of digesting glucose, fat, and protein as well as can be used as a dietary enhancer. Studies have shown that the human body contains about $0.03 \mathrm{mg} / \mathrm{L}$ of $\mathrm{Cr}$ and needs to supplement $15-200 \mu \mathrm{g}$ every day [15].

The lack of $\mathrm{Cr}$ may cause diseases such as arterial hypertension and cardiovascular disease. Meanwhile, $\mathrm{Cr}$ can also stimulate plant growth to increase yield. However, high doses of chromium, both $\mathrm{Cr}$ (III) and $\mathrm{Cr}$ (VI), are harmful to human health. Moreover, $\mathrm{Cr}(\mathrm{VI})$ is much more toxic than $\mathrm{Cr}(\mathrm{III})$, which is a strong mutagenic substance. Symptoms such as vomiting, diarrhoea and headache will occur when $\mathrm{Cr}(\mathrm{VI})$ is mildly toxic, but in severe cases, it can induce lung cancer and nasopharyngeal cancer. The dangerous dose of $\mathrm{Cr}(\mathrm{VI})$ is about $1-2 \mathrm{~g}$, and the median lethal dose (LD50) of $\mathrm{Cr}$ (III) and $\mathrm{Cr}$ (VI) is 1900-3000 $\mathrm{mg} / \mathrm{kg}$ and $50-100 \mathrm{mg} / \mathrm{kg}$, respectively [15].

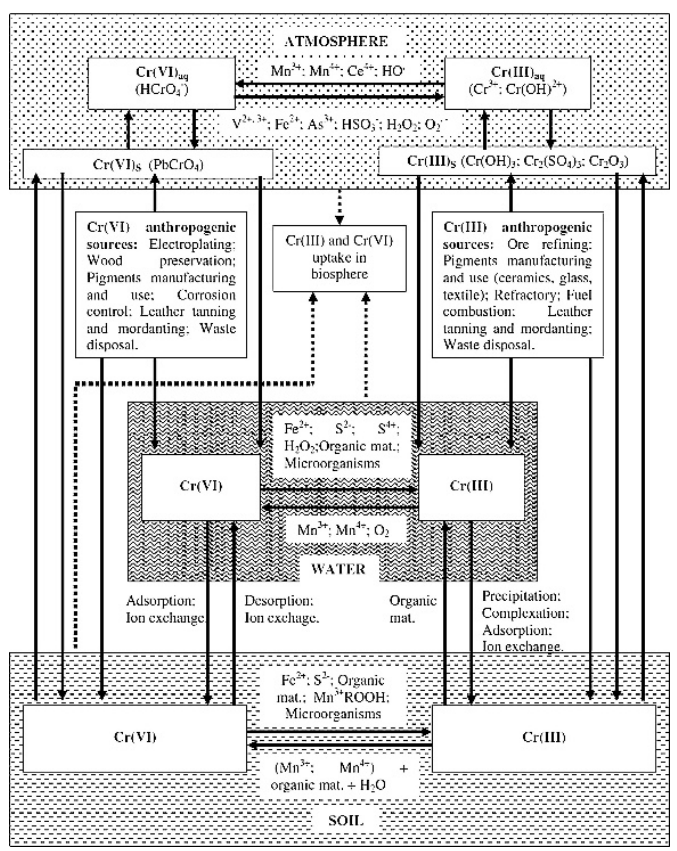

Figure 2. Biogeochemical cycle of $\mathrm{Cr}$ in atmosphere, soil, and water [14]

\section{Mercury}

Mercury is a natural element that widely found in biosphere with the form of metal elements, inorganic and organic matters. As an element with a variety of economic uses, metallic mercury and its compounds are widely used in chemistry, medicine, metallurgy, electronic instruments, military and other precision and technological fields [16]. Due to inappropriate mercury emissions, humans are exposed to various forms of mercury pollution in their daily lives. Mercury-containing wastewater poses a potential threat to human health caused by the accumulation of organisms. The most serious mercury poisoning accident was the Minamata Disease in 1956, which aroused continuous concern about mercury pollution worldwide. 


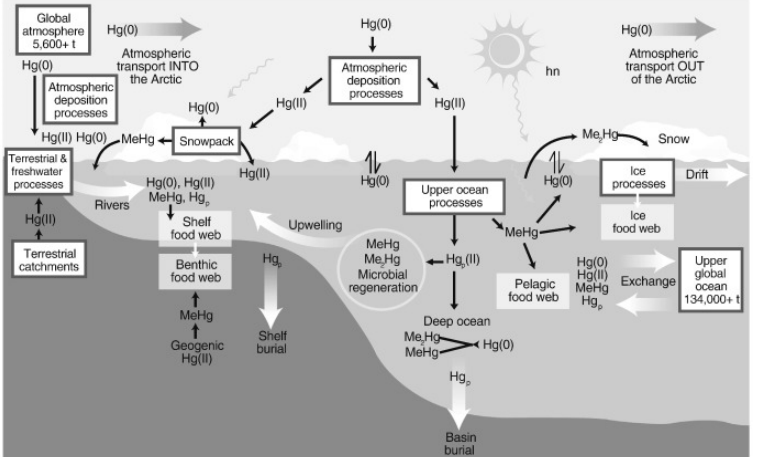

Figure 3. Distribution pathways of $\mathrm{Hg}$ to Arctic marine waters and their transformations [17]

There are many sources of mercury pollution in nature, mainly from natural sources and man-made sources. The major pathways and transformations of Mercury in Arctic was shown in Fig. 3, and the most existing form was inorganic $\mathrm{Hg}(\mathrm{II})$ [17]. Natural sources include volcanic activity, geothermal hot springs, natural weathering, soil emissions, and vegetation release. Typical man-made sources of mercury pollution include: (1) Medical waste: mercury alloys and compounds are used in dental filling materials and disinfectants; (2) Metallurgical industry: Mercury is used to dissolve other metals to form amalgam to extract gold, silver, thallium and other metals; (3) Electrical instrument industry: Mercury is used to make mercury salt dry batteries, mercury lamps, barometers, diffusion pumps, mercury switches and thermometers and other physical instruments; (4) Precision high-tech fields: Mercury is used for precision casting molds, plutonium nuclear reactor coolant, cadmium-based bearing alloys, etc.; (5) Fossil fuel combustion: The process of coal burning and garbage incineration in power plants is considered to be the main cause of global mercury emissions [18]. In view of the threats mercury poses to the environment and organisms, the United Nations Environment Programme adopted the Minamata Convention in 2013, an international convention aimed at global control and reduction of mercury emissions, and made detailed regulations on specific emission limits to reduce mercury exposure.

The prevention and control of mercury in water bodies should not only pay attention to the source of mercury pollution in the environment, but also focus on understanding its geochemical cycle in nature. Since the Minamata Convention came into effect, the source of mercury release has been effectively controlled. However, human activities may lead to the re-release of mercury and thus increase the efficiency of mercury methylation. In addition, the form of mercury gas makes it possible for long-distance transmission, even in remote areas like the Arctic without exhaust emissions. Moreover, changes in natural climate and land utilization have made it more difficult to determine the mercury cycle, methylmercury bioavailability, and mercury migration and transformation in the biological chain [19]. Therefore, more detailed and up-to-date data on the distribution and the health effects of mercury are needed to provide a reliable basis for assessing the hazard risk as well as predicting the migration and transformation of mercury, which will play an extremely beneficial role in preventing and controlling mercury pollution.

\section{Lead}

In recent years, with the rapid development of the steel, battery and gasoline industries, toxic heavy metal lead has been released into the environment. When the accumulation of lead in the water environment reaches the safety limit, it will cause great harm to the human body, aquatic organisms and crops. With the frequent occurrence of a series of lead pollution problems, scientists continue to conduct a more in-depth discussion on the harm of lead and environmental behaviour.

Generally speaking, in natural water bodies or deep seas, the lead content is not high. However, the lead concentration in coastal waters and lead mine drainage areas has generally increased, indicating that the contribution rate of lead pollution mainly comes from emissions from industries and households as well as the runoff from mineralized areas. With excellent physical and chemical properties, lead is widely used in smelting, painting, medicine and cosmetics [20]. For example, tetraethyl lead is added to gasoline to improve explosionproof properties; metallic lead can let the paint brighter and moisture-resistant; and lead can also help cosmetics achieve brightening and whitening effects [21]. However, lead is relatively toxic in heavy metals, which can act on various systems and organs of the human body and is mainly neurotoxic. The toxicity of lead is closely related to its form and solubility in water. Lead nitrate and lead acetate are soluble in water and easily absorbed by human bodies; solid lead oxide and alkaline lead sulfate are easily soluble in acid and have high toxicity; lead sulfide and lead chromate have low toxicity because of the poor solubility; organic lead such as tetraethyl lead is more toxic than inorganic species. The accumulate of lead in the kidneys, brain, muscles, and bones, inevitably cause damage to the nervous, bone marrow hematopoietic, digestive, cardiovascular, kidney and reproductive as well as immune system. Both inorganic and organic lead at high levels in human body can cause deformity, cancer, genetic mutation and poor embryonic development [2123]. After long-term exposure, lead may cause human diseases such as anaemia and hepatitis even at low level. According to the stipulation of WHO and USEPA, the concentrations of $\mathrm{Pb}$ in safe drinking water should be less than $10 \mu \mathrm{g} / \mathrm{L}$.

\section{Strontium}

Alkaline earth metal Strontium can be easily oxidized into a stable bivalent $\mathrm{Sr}(\mathrm{II})$. Strontium can be existed in natural environment as ${ }^{84} \mathrm{Sr},{ }^{86} \mathrm{Sr},{ }^{87} \mathrm{Sr},{ }^{88} \mathrm{Sr}$, and 31 unstable isotopes [24]. Among them, ${ }^{90} \mathrm{Sr}$ has the longest life and it is the most common fission product of ${ }^{235} \mathrm{U}$ and ${ }^{239} \mathrm{Pu}$, and also the most common radioactive pollutant in wastewater.

In addition to nuclear power plant operation, uranium and thorium mining, nuclear weapon production, strontium is also widely used in ceramics, sugar, medicine, chemical industry and other industrial fields [25]. Therefore, industrial production of strontium-containing 
radioactive wastewater should also be given high attention. Strontium is an indispensable trace element of human body, which is a normal part of human bones and can help enhance the excretion of sodium [26]. In addition, some radioisotopes of strontium also play an important role in pain treatment. However, since $\mathrm{Sr}$ is related to calcium (Ca), they have similar chemical properties. In biology, excessive $\mathrm{Sr}$ may interfere with calcium absorption and metabolism. After entering the human body, the radioactive ${ }^{90} \mathrm{Sr}$ will form ${ }^{90} \mathrm{Sr}_{3}\left(\mathrm{PO}_{4}\right)_{2}$ through ion exchange with the $\mathrm{Ca}$ in the bone, which accumulates in the inorganic substance of the bone marrow cavity, thus seriously radiating the hematopoietic stem cells in the bone marrow cavity, and leading to a significant decrease in the number of white blood cells, red blood cells and platelets. Long-term ${ }^{90} \mathrm{Sr}$ radiation can cause leukaemia, osteosarcoma and other diseases. Although nonradioactive $\mathrm{Sr}$ is not radioactive and is also less toxic, it can seriously interfere with the calcification process of bone tissue, resulting in spontaneous fractures and systemic osteoporosis. Moreover, after radioactive strontium contaminate the mother, strontium can be transferred to the baby through placenta and milk, thus causing serious harm.

\section{Conclusion}

In this revies, we summarized the basic information of heavy metal ions (chromium, arsenic, lead, mercury, and strontium) in wastewater. The chemical status, biological toxicity, and migration were briefly introduced. Overall, the purification technology for practical applications to remediate these highly toxic and carcinogenic pollutants. In foreseeable future, advanced purification technology will be utilized for heavy metal removal, and this review could provide basic information and environmental mechanism of mentioned pollutants to protect public health and environmental, and fulfil this task.

\section{Acknowledgments}

The work was financially supported by National Natural Science Foundation of China (11875028).

\section{References}

1. J. O. Nriagum, Science 12, 272 (1996)

2. H. Zhen, L. Jia, C. Huang, Y. Qiao, J. Li, H. Li, Q. Chen, Y. Wan, Environ. Pollut 263, 114552 (2020)

3. E. G. Farmaki, N. S. Thomaidis, Global Nest J 10, 366 (2008)

4. P. U. Singare, R. M. Mishra, M. P. Trivedi, Front. Sci 2, 28 (2012)

5. C. Z. Ledezma, D. N. Bolagay, F. Figueroa, E. Z. Ledezma, M. Ni, F. Alexis, V. H. Guerrero, Environ. Technol. Inno 22, 101504 (2021)

6. J. P. Vareda, A. J. M. Valente, L. Durães, J. Environ. Manage 246, 101 (2019)

7. B. K. Mandal, K. T. Suzuki, Talanta 58, 201 (2002)
8. P. L. Smedley, D. G. Kinniburgh, Appl. Geochem. 17,517 (2002)

9. S. Aksentijević, J. Kiurski, M. V. Vasić, Environ. Monit. Assess. 184, 335 (2012)

10. R. Eisler, Rev. Environ. Contam. T 180, 133 (2004)

11. P. Tchounwou, J. Centeno, A. Patlolla, Mol Cell Biochem 255, 47 (2004).

12. S. R. Mitra, A. Basu, D. N. Mazumder, Environ. Health Perspect. 112, 1104 (2004)

13. H. Onishi, E. B. Sandell, Geochim. Cosmochim. Ac. 7, 1 (1955)

14. M. Gheju, Water Air \& Soil Poll 222, 103 (2011)

15. K. G. Pavithra, V. Jaikumar, P. S. Kumar, P. Sundarrajan, J. Clean. Prod. 228, 580 (2019)

16. J. Yu, B. Yue, X. Wu, Q. Liu, F. Jiao, X. Jiang, X. Chen, Environ. Sci. Pollut. Res 23， 5056 (2016)

17. B. Braune, J. Chételat, M. Amyot, T. Brown, M. Clayden, M. Evans, A. Fisk, A. Gaden, C. Girard, A. Hare, J. Kirk, I. Lehnherr, R. Letcher, L. Loseto, R. Macdonald, E. Mann, B. McMeans, D. Muir, N. O'Driscoll, A. Poulain, K. Reimer, G. Stern, Sci. Total Environ. 509-510, 67 (2015)

18. L. T. Budnik, L. Casteleyn, Sci. Total Environ. 654, 720 (2019)

19. E. Ha, N. Basu, S. Bose-O'Reilly, J. G. Dorea, E. Mcsorley, M. Sakamoto, H. M. Chan, Environ. Res 152, 419 (2016)

20. G. D. Corder, A. Golev, D. Giurco, Miner. Eng 76, 2 (2015)

21. J. D. O. Brandão, O. J. Okonkwo, M. Sehkula, R. M. Raseleka, Toxicol. Environ. Chem. 94, 70 (2012)

22. G. Lockitch, Clin. Biochem 26, 371 (1993)

23. P. C. Hsu, Y. L. Guo, Toxicology 180, 33 (2002)

24. S. Voerkelius, G. D. Lorenz, S. Rummel, C. R. Quétel, G. Heiss, M. Baxter, C. Brach-Papa, P. DetersItzelsberger, S. Hoelzl, J. Hoogewerff, E. Ponzevera, M. Van Bocxstaele, H. Ueckermann, Food Chem. 118, 933 (2010)

25. A. Ahmadpour, M. Zabihi, M. Tahmasbi, T. R. Bastami, J. Hazard. Mater. 182, 552 (2010)

26. V. Zaichick, Biol. Trace Elem. Res. 153, 84 (2013) 